\title{
A physiology-based perspective on high-flow nasal cannula oxygen delivery in the critically ill patient
}

\author{
Gustavo A Cortes-Puentes, MD, Richard A Oeckler MD, PhD
}

The heterogeneous lung injury pattern seen in hypoxic respiratory failure due to the acute respiratory distress syndrome (ARDS) is both a cause and effect of altered pulmonary mechanics and gas exchange. ${ }^{1}$ In an ideal world, an appropriately timed, non-invasive oxygen delivery method, such as non-invasive positive airway pressure ventilation (NIV) or high-flow nasal cannula (HFNC), would not only compensate for these deficits, but also mitigate the negative and additive effect of air hunger upon respiratory drive and the risk for ventilator-induced lung injury (VILI) in the already compromised respiratory system. ${ }^{1,2}$ Lowtidal volume ventilation is a cornerstone of a lung protective ventilation strategy precisely for these reasons, and has been shown to reduce mortality. Although not established for spontaneously breathing patients, the available literature ${ }^{3,4}$ supports a conservative tidal volume strategy, even for patients without $\mathrm{ARDS},{ }^{3}$ and especially for those who are young and more likely to generate large tidal volumes $\left(\mathrm{V}_{\mathrm{T}}\right){ }^{4}$ Yet with HFNC clinicians lose the opportunity to estimate or control tidal volume, thus surrendering a key parameter for targeting lung strain and stress, minimizing cycling frequency of shear forces, and preventing VILI.

In contrast to passive mechanical ventilation, spontaneous breathing necessarily requires the development of negative pleural pressure $\left(\mathrm{P}_{\mathrm{PL}}\right){ }^{5}$ Thus for any given tidal volume, transpulmonary pressure $\left(\mathrm{P}_{\mathrm{TP}}\right.$; defined as alveolar minus pleural pressure) will be larger. Theoretically, this increased distending pressure could facilitate the recruitment of dependent lung units throughout the tidal cycle, ${ }^{3}$ improving compliance and reducing work of breathing. This would seem to argue for spontaneous breathing as a potential recruitment tool, allowing a larger number of functional lung units to be exposed to a given $\mathrm{V}_{\mathrm{T}}$, and, therefore, against any potential harm of high $\mathrm{V}_{\mathrm{T}}$ during spontaneous breathing, as may occur under HFNC. The delivery of uncontrolled and disproportioned $V_{T}$ relative to the heterogeneous "baby lung" coincides with large local changes in transpulmonary pressure and harmful lung strains ${ }^{1}$ compounded by interdependence. ${ }^{6}$ Very often, clinicians face the dilemma of whether to tolerate high $V_{\mathrm{T}}$ while the patient's work of breathing remains increased in the absence of positive pressure NIV. Recently Protti and Gattinoni et al have linked high strain rates with an increased risk of pulmonary edema by augmented lung viscoelastic behavior (parenchymal energy dissipation) and posit that this might also explain why large strains injure healthy lungs. ${ }^{7}$ In principle, these findings suggest that selecting strain and strain rates that produce small dynamic true driving pressure ${ }^{8}$ changes (tidal changes in $\mathrm{P}_{\mathrm{TP}}$ ) is not feasible when using HFNC.

A salient study regarding the use of HFNC in acute hypoxic respiratory failure reported a significant difference in favor of oxygen delivery by HFNC in 90-day mortality; yet when compared to standard oxygen delivery or NIV, the use of HFNC did not result in a significantly different intubation rate. ${ }^{9}$ This may in part be due to a lack of criteria or guidelines for the determination of treatment failure, and the lack of clear recommendations for when to escalate therapy to endotracheal intubation, heavy sedation, and paralysis to take control of work of breathing and oxygen demand. Furthermore, the ability of HFNC to augment work of breathing and $\mathrm{O} 2$ delivery is presumed to be at least partially mediated by positive end-expiratory pressure (PEEP), yet the ability for HFNC to generate PEEP at the level of the alveolus remains poorly understood and highly controversial.

For instance, Parke et al. found a positive correlation $(\sim 10 \mathrm{~L} / \mathrm{min}=\sim 1.2 \mathrm{cmH} 2 \mathrm{O})$ between HFNC flow rate and nasopharyngeal PEEP, 10 
but patients receiving enough flow $(60 \mathrm{~L} / \mathrm{min})$ to generate the equivalent of $5 \mathrm{~cm} \mathrm{H} 2 \mathrm{O}$ or more by NIV under this hypothesis in reality had significantly lower $\mathrm{PaO} 2$ than the NIV group for a given FiO2. ${ }^{11}$ It is also rare, at least at our institution, to see chin straps to prevent flow (and pressure loss) through the oropharynx employed on a regular basis. In total, the effects of HFNC on alveolar PEEP are likely variable at best. We do know, however, that distally measured airway pressures within closed circuits of mechanically ventilated patients may correlate poorly with actual lung stress under commonly encountered clinical scenarios (e.g., intra-abdominal hypertension, asymmetric lung injury ${ }^{12}$ ). Thereby, nasopharyngeal PEEP levels generated by HFNC most likely cannot compensate under these conditions, especially with a variably open and closed circuit interface i.e., the patient's oropharynx. Although the severity of lung injury may be the major predictor of success for HFNC and/or NIV strategies, ${ }^{4,9}$ other parameters such as body habitus (e.g., severe obesity) and reduced chest wall compliance (e.g., intra-abdominal hypertension), should be factored when deciding between transitory oxygen delivery via HFNC vs. early appropriate intubation.

In conclusion, HFNC is an attractive option for oxygen delivery in the patient with nonhypercapnic hypoxemic respiratory failure. Although the mechanism is elusive, improvements in work of breathing, oxygenation, and outcome reported in highly selected patient populations warrant further investigation. In appropriate patients treated with HFNC, we recommend close observation with predetermined criteria for therapeutic failure and escalation to minimize driving pressure, assure adequate oxygenation, and prevent VILI.
Author Affiliation: Author affiliations- Gustavo A CortesPuentes is a fellow in the Department of Pulmonary and Critical Care Medicine, Mayo Clinic, Rochester, MN. Richard A Oeckler is a faculty member in that department.

Submitted: 9/23/2016

Published electronically: 10/15/2016

Conflict of Interest Disclosures: none

Corresponding Author: Richard A Oeckler

Contact Information: Oeckler.richard@mayo.edu

DOI: 10.12746/swrccc2016.0416.211

\section{REFERENCES}

1. Chiumello D, Carlesso E, Cadringher P, et al. Lung stress and strain during mechanical ventilation for acute respiratory distress syndrome. Am J Respir Crit Care Med 2008; 178:346-355.

2. Ozyilmaz E, Ugurlu AO, Nava S. Timing of noninvasive ventilation failure: causes, risk factors, and potential remedies. BMC Pulm Med. 2014; 14:19.

3. Pelosi P, Goldner M, McKibben A, et al. Recruitment and derecruitment during acute respiratory failure: an experimental study. Am J Respir Crit Care Med 2001; 164: 122-130.

4. Serpa Neto A1, Simonis FD, Barbas CS, et al. Association between tidal volume size, duration of ventilation, and sedation needs in patients without acute respiratory distress syndrome: an individual patient data meta-analysis. Intensive Care Med 2014; 40(7):950-957. 5. Milic-Emili J, Mead J, Turner JM, et al. Improve technique for estimating pleural pressure from esophageal balloons. J Appl Physiol 1964; 19: 207-211.

6. Mead J, Takishima T, Leith D. Stress distribution in lungs: a model of pulmonary elasticity. J Appl Physiol 1970; 28:596-608 7. Protti A1, Maraffi T, Milesi M, et al. Role of strain rate in the pathogenesis of ventilator-induced lung edema. Crit Care Med 2016; 44(9):e838-45.

8. Cortes-Puentes GA1, Gard KE, Adams AB, et al. Value and limitations of transpulmonary pressure calculations during intraabdominal hypertension. Crit Care Med 2013; 41(8):1870-1877. 9. Frat JP, Ragot S, Thille AW, et al. High-flow nasal cannula oxygen in respiratory failure. N Engl J Med 2015; 373

(14):1374-1375.

10. Parke R, Bloch A, McGuinness S. Effect of very-high-flow nasal therapy on airway pressure and end-expiratory lung impedance in healthy volunteers. Respir Care 2015; 60(10):1397-1403.

11. Vargas F, Saint-Leger M, Boyer A, Bui NH, Hilbert G.

Physiologic effects of high-flow nasal cannula oxygen in critical care subjects. Respir Care 2015; 60(10):1369-1376.

12. Cortes-Puentes GA, Keenan JC, Adams AB, et al. Impact of chest wall modifications and lung injury on the correspondence between airway and transpulmonary driving pressures. Crit Care Med 2015; 43(8):287-295. 